\title{
A SAÚDE COMO METACAPACIDADE: REDEFININDO O BEM JURÍDICO
}

\section{Ian Pimentel Gameiro 1}

\section{Resumo}

O artigo tem como objetivo, por um lado, redefinir o bem jurídico-constitucional 'saúde' a partir da proposta de Venkatapuram e, por outro, discutir algumas das suas implicações normativas fundamentais. Para tanto, revisamse as bases teóricas utilizadas por Venkatapuram (a teoria das capacidades de Amartya Sen e Nussbaum, e o conceito holístico de saúde de Nordenfelt), propõem-se algumas readequações ao conceito e, por fim, analisam-se as suas principais implicações. Emprega-se, prioritariamente, o método da revisão de literatura.

Palavras-chave: Teoria das Capacidades. Conceito Holístico de Saúde. Saúde como Metacapacidade. Venkatapuram. Direitos Sociais.

\section{INTRODUÇÃO}

O primeiro desafio que um estudo dogmático acerca do direito fundamental à proteção da saúde deve enfrentar consiste, segundo entendemos, em propor uma definição conceitual para o bem jurídico 'saúde’ seguida da determinação, consoante tal definição, do âmbito normativo (ou domínio da realidade tutelado) do direito respectivo (art. 196, CR).

No desenvolvimento desta tarefa, parece-nos que três exigências epistemológicas se impõem. Em primeiro lugar, a definição deve possibilitar a verificação objetiva do estado de sanidade de uma determinada pessoa ou grupo social - o que o modelo biomédico ainda muito utilizado parece atender com exatidão. Em segundo lugar, deve necessariamente levar em conta os fatores não orgânicos ou biológicos influentes sobre o nível de sanidade experimentado (acesso à educação, informação, alimentos, posse de recursos econômicos, etc.). Em terceiro e último lugar, o conceito deve possibilitar a sua operacionalização jurídica pelo intérprete e aplicador da norma constitucional.

Aquilo que nos propomos a tratar - a redefinição do conceito de saúde para entendê-lo agora uma

\footnotetext{
${ }^{1}$ Doutorando em Ciências Jurídico-Filosóficas e Mestre em Ciências Jurídico-Políticas, com menção em Direito Constitucional, pela Faculdade de Direito da Universidade de Coimbra (Portugal). Membro do Grupo de Investigação 'Transparencia, Buena Gobernanza y Comunicacíon' da Universidad Complutense de Madrid (Espanha). Revisor do Periódico 'Revista Online Especializada en Derecho de la Comunicación' (Universidade Complutense de Madrid/ES). Associado à Associação Nacional de Direitos Humanos, Pesquisa e Pós-Graduação - ANDHEP e ao Conselho Nacional de Pesquisa e Pós-Graduação em Direito CONPEDI.E-mail: pimentel.ian@hotmail.com
} 
metacapacidade - reflete precisamente esta preocupação em saber qual o melhor significado deste bem jurídico capaz de cumprir com estas exigências essenciais.

Com efeito, a ideia de se conceber a saúde como uma metacapacidade surge, originariamente, da tese de doutoramento apresentada por Sridhar Venkatapuram à Universidade de Cambridge em 2007. Conquanto tenha avançado em muitos pontos e nos pareça ter superado deficiências apontadas em concepções rivais, consideramos que essa definição carece ainda de algumas correções e retificações, sendo este o precisamente o contributo que propomo-nos a oferecer.

Assim, num percurso dividido em cinco etapas essenciais, e cujo método primordial é o da revisão de literatura, percorremos e analisamos as bases teóricas sobre as quais sustenta-se o pensamento de Venkatapuram (teoria das capacidades de Amartya Sen e Martha Nussbaum, e a teoria da saúde de Nordenfelt), para depois daí apresentar a sua proposta, corrigi-la, e finalmente extrair as suas implicações mais relevantes.

\section{CAPACIDADES, LIBERDADE E O LUGAR DE AMARTYA SEN}

A abordagem das capacidades começa a ser construída em princípios da década de 1980, a partir das deficiências reconhecidas por Amartya Sen nas teorias da justiça àquela altura dominantes.

Tudo inicia quando Sen observa que a tarefa primordial de toda teoria da justiça é tentar conceder alívio ao desconforto moral que se sente quando, após o exame da situação concreta de um indíviduo segundo um critério qualquer, conclui-se pela inaceitabilidade do seu estado de desvantagem.

Considerando que, pelo menos para todas as teorias até então construídas, este alívio teria significado a realização de alguma espécie de distribuição mais adequada do objeto que cada qual considerava como a grandeza particularmente mais importante, Sen conclui que o grande problema teórico passava a ser, efetivamente, o de saber qual seria o critério ou foco informacional mais adequado para julgar a vantagem e a desvantagem dos indivíduos (SEN, 1980, p. 197; SEN, 1992, p. 12-16).

A essa questão procurou responder, sobretudo, em seu Equality of What? (SEN, 1980), ocasião em que promoveu a introdução do conceito de 'capacidades básicas' no âmbito da filosofia política e o defendeu como sendo o critério adequado para julgar a vantagem individual e a justiça em uma sociedade.

Com efeito, naquele texto Sen passa a defender que a igualação dos indivíduos deveria girar em torno da sua oportunidade efetiva para realizarem minimamente algumas coisas básicas necessárias à sua sobrevivência (as capacidades básicas). Isto é, todos os indivíduos deveriam ter a oportunidade, a igual oportunidade, de poder realizar em níveis mínimos, caso assim quisessem, coisas elementares e urgentes para manutenção da sua existência (SEN, 1980, p. 218; SEN, 2007, p. 279-280).

Para Sen, é sensivelmente importante que as pessoas tenham a possibilidade de escolher, por exemplo, 
entre jejuar por motivos religiosos ou manter uma alimentação normal; inaceitável, para si, é obrigá-las a terem de escolher por jejuar, quase sempre por motivos econômicos, em razão de não terem a possibilidade de dispor de níveis mínimos de alimento caso decidam por manterem-se nutridas.

Convém registrar neste ponto que Sen não faz, e nunca fez, a defesa de uma suposta igualdade de capacidades tal como, equivocadamente, costuma ser assinalado por uma parte da doutrina. Em Equality of What? (SEN, 1980, p. 219), Capability and Well-Being (SEN, 2007, p. 279) e em A Ideia de Justiça (SEN, 201 1, p. 331) apresenta três razões distintas que esclarecem a rejeição desta posição.

Resumido-se o seu pensamento em dois pontos, considera, por um lado, não ser possível elaborar um conjunto cerrado de capacidades em termos das quais os indivíduos deveriam ser totalmente igualados - daí porque defende, na verdade, uma igualdade no sentido de igual oportunidade mínima de gozo das capacidades culturalmente consideradas essenciais; e, por outro, entende que a igualdade não poderia ser reduzida a um único espaço - entre eles o das capacidades -, em virtude da necessidade de também valorizar-se a exigência de equidade processual (tratar pessoas diferentes de modo diferente).

Ora, e o que são, afinal, as capacidades ou a capacidade? Com efeito, Sen observa que a liberdade possui dois aspectos diferentes, como se fossem duas faces de uma moeda, complementares e intrinsecamente importantes para a vida humana. O primeiro desses aspectos liga-se à ideia de liberdade como processo que permite a escolha e a ação. Fica bem entendido que por esta ideia Sen pretende ressaltar a noção de liberdade como ausência de interferências e restrições exteriores no momento da tomada de decisão, como, por exemplo, a liberdade das pessoas poderem eleger os seus governantes sem que nenhum deles exerça influência sobre o seu juízo e decisão (SEN, 2000, p. 33-34; SEN, 2011, p. 262-263).

O segundo aspecto, esse particularmente importante para Sen, prende-se com a ideia de liberdade enquanto oportunidade substantiva das pessoas em poderem buscar a realização dos seus planos e objetivos de vida. Por essa noção, Sen pretende associar a ideia de liberdade à oportunidade real que as pessoas têm para, diante de múltiplos e ilimitados estilos de vida, fazer a opção por um ou por alguns especialmente valorizados em razão do seu planejamento de vida (SEN, 2000, p. 33-34; SEN, 2011, p. 262-263).

A liberdade constitui para Sen, portanto, de um lado, a ausência de intromissões no processo de decisão, e, de outro, a oportunidade real de poder-se optar por um ou alguns dentre vários estilos de vida especialmente valorizados em razão do planejamento de vida que cada ser humano traça para si.

A capacidade, e daí porque Sen rejeita afirmativamente a possibilidade de se igualarem os indivíduos nesse quesito, representa a possibilidade (liberdade) concreta que um indivíduo possui de poder converter em realização efetiva um determinado estilo de vida especialmente valorizado, a oportunidade de poder optar por um dentre variados estilos de vida. 
Isto é, a vida de uma pessoa - argumenta o autor - constitui uma combinação de vários seres e fazeres, que vão desde as coisas mais elementares da vida, como estar bem nutrido, livre de doenças ou alojado em uma confortável moradia, às coisas mais complexas, como ter autorrespeito ou fazer parte da vida comunitária (NUSSBAUM; SEN, 1993, p.3).

A esses diversos "seres" e "fazeres" constitutivos da vida humana Sen intitulou funcionamentos/funcionalidades. A capacidade de uma pessoa representa a sua oportunidade (liberdade) de poder escolher concretizar outros "seres" e "fazeres" - funcionamentos - especialmente valorizados por si em razão do seu projeto de vida.

Sistematizando objetivamente essa ideia, ter-se-ia que:

1. Funcionamentos: representam um "ser" ou "fazer" (uma unidade, digamos) constitutivo do estado atual de uma pessoa, a exemplo de ser partícipe da vida da comunidade, estar adequadamente nutrido, estar devidamente alojado, etc.

2. Vetor de Funcionamentos: representa todas as unidades de "ser" ou "fazer" reveladoras do estado atual de uma pessoa. Isto é, descreve todos os "seres" e "fazeres" que constituem o estilo de vida atual e realizado de uma pessoa. Cada vetor de funcionamento existente representa um determinado estilo de vida diferente e possível.

3. Capacidades: representam a oportunidade (liberdade) que uma pessoa tem para escolher e realizar concretamente uma unidade de "ser" e/ou "fazer", ou um vetor de funcionamento total, por si valorizada em razão do seu plano de vida. Ou seja, é a oportunidade de "ser" ou "fazer" alguma coisa ainda não realizada, mas que é valorizada em razão de um planejamento de vida, como, por exemplo, ter a capacidade de se alojar adequadamente ("ser"/"fazer" valorizado) em razão de no momento estar-se desalojado ("ser" / "fazer" constitutivo de um estilo de vida atual).

4. Conjunto Capacitório: representa o conjunto de vetores de funcionamento que uma pessoa tem disponível para escolher (oportunidade) conforme o seu projeto de vida. Pode-se afirmar que o conjunto capacitório constitui o leque de opções a serem consideradas por uma pessoa após lhe dirigirem a seguinte pergunta: 'O que você deseja ser?' (CLARK, 2006, p. 4).

É possível identificar em toda a obra de Sen a remissão a esses conceitos básicos. No entanto, é imperioso esclarecer que a despeito de tê-los estabelecido formal e sistematicamente, sobretudo o conceito de capacidades e o de conjunto capacitório, Sen costuma utilizar a expressão 'capacidades' no sentido, ou com referência, ao conjunto capacitório.

Assim, quando afirma ser necessário avaliar a desvantagem individual a partir das capacidades do indivíduo, a sua intenção é deixar claro que a desvantagem de um indivíduo deve ser medida a partir da sua 
oportunidade (capacidade) real em poder concretizar o estilo de vida (dentre todas as possibilidades a si disponíveis) que tem razão para valorizar.

\section{CAPACIDADES HUMANAS CENTRAIS: DIÁLOGOS COM MARTHA NUSSBAUM}

Embora tenha se revelado como uma via bastante interessante para a avaliação da justiça nas sociedades, por essas e por outras razões não exploradas neste texto, a abordagem das capacidades de Sen não deixou de ser criticada.

Martha Nussbaum, grande entusiasta e participante ativa na construção desta perspectiva, acusa Sen de ter deixado escapar um problema central relacionado ao fato de que o exercício de algumas liberdades humanas limita o exercício de outras, como, por exemplo, "a liberdade dos negócios poluírem o ambiente limita a liberdade dos cidadãos desfrutarem de um ambiente despoluído; a liberdade dos proprietários de manter suas terras limita projetos de reforma fundiária que podem ser primordiais para as liberdades dos pobres" (REICHER, 2009, p. 45), e essa são questões que não poderiam deixar de ser enfrentadas.

Para Nussbaum, uma adequada teoria da justiça social deve possuir algum nível de comprometimento ético com a identificação e delimitação de liberdades humanas centrais se estiver disposta a realizar o propósito político ao qual se dispôs (NUSSBAUM, 2003, p. 1-2).

Isso porque, não sendo assim, a justiça social pretendida, a exemplo da justiça de gênero, sempre irá depender da factibilidade de uma mudança nos padrões representativos, interpretativos e comunicacionais historicamente enraizados na cultura de determinados povos, como é o caso da representação social feminina na Índia ou na Arábia Saudita, por exemplo.

Em resumo, Martha Nussbaum se distancia de Sen fundamentalmente por compreender que não se pode relegar à comunidade, com exclusividade, a tarefa de determinar quais são as capacidades humanas centrais com as quais os indivíduos devem contar, embora reconheça o papel essencial que a sociedade exerce nessa definição.

Por essa razão, avança na matéria e propõe uma lista de dez capacidades humanas centrais que julga corresponder às exigências mínimas da dignidade humana:

1. Vida: Ser capaz de viver até o fim da vida humana de duração normal, sem morrer prematuramente;

2. Saúde corporal: Ser capaz de ter boa saúde, incluindo a saúde reprodutiva; estar adequadamente nutrido; ser capaz de ter um abrigo adequado;

3. Integridade corporal: Ser capaz de se mover livremente de um lugar para outro; de estar seguro de assaltos violentos, incluindo agressão sexual; ter oportunidades para a satisfação sexual e escolha para fins de reprodução;

4. Sentimento, imaginação e pensamento: Ser capaz de usar os sentidos, de imaginar, pensar, e raciocinar - e para fazer essas coisas de forma humana, uma maneira informada e cultivada por uma educação adequada ser capaz de usar a imaginação e 
pensamento em conexão com a experiência, e produzindo obras expressivas e eventos autênticos; ser capaz de utilizar a imaginação com garantias de liberdade de expressão com respeito ao discurso político e artístico e à liberdade de exercício religioso, sendo capaz de ter experiências agradáveis e evitar a dor não benéfica.

5. Emoções: Ser capaz de estabelecer vínculos com coisas e pessoas; ser capaz de amar aqueles que amam e cuidam de nós, sendo capaz de sofrer a sua ausência, para experimentar saudade, gratidão e raiva justificada, não tendo, portanto, um emocional marcado ou aprisionado pelo medo ou ansiedade.

6. Razão prática: Ser capaz de formar uma concepção do bem e se envolver em uma reflexão crítica sobre o planejamento da própria vida. (Isto implica a proteção da liberdade de consciência.)

7. Afiliação: Ser capaz de viver com e em relação aos outros, reconhecer e mostrar preocupação com os outros seres humanos e de se engajar nas várias formas de interação social, sendo capaz de imaginar a situação de outro e ter compaixão por essa situação, tendo a capacidade de exercício da justiça e a amizade; ser capaz de ser tratado como um ser digno de quem valor é igual à dos outros.

8. Outras espécies: Ser capaz de viver com preocupação em relação aos animais, plantas, e com o mundo da natureza.

9. Diversão: Ser capaz de rir, brincar e desfrutar de atividades recreativas.

10. Controle sobre o ambiente: (A) política: ser capaz de participar nas escolhas políticas que efetivamente governam a própria vida, tendo os direitos de participação política, liberdade de expressão e liberdade de associação; (B) material: ser capaz de manter a propriedade (tanto os imóveis como os móveis), tendo o direito de procurar emprego numa base de igualdade com os outros (NUSSBAUM, 2011, p. 33-34; OLIVEIRA; GOMES, 2013, p. 85-86).

Sen, por sua vez, não reconhece a crítica de Nussbaum, tampouco a adequabilidade de sua lista, esclarecendo à partida que o "compromisso com a autodeterminação e os processos democráticos na filosofia liberal milita contra qualquer especificação do direito ou do bom” (tradução nossa) (VENKATAPURAM, 2007, p. 99).

Para Sen, estabelecer uma lista com capacidades básicas centrais, por mais importantes que elas sejam para a vida humana, implicaria em uma limitação do que as pessoas poderiam ou não poderiam ser e fazer, e a abordagem das capacidades, consequentemente, acabaria por violar aquilo que mais pretende proteger: a liberdade.

Não obstante, o estabelecimento de uma tal lista de capacidades não poderia ter sido realizado se na sua elaboração se tivesse levado em conta o dever de respeito pela pluralidade e incomensurabilidade de múltiplos bens morais (VENKATAPURAM, 2007, p. 99).

Ora, não nos parece que o conjunto de capacidades básicas identificadas por Martha Nussbaum possa ser acusado de veicular um tipo específico de vida boa somente pelo fato de ter sido elaborado por uma pessoa cuja formação cultural está inserida no contexto da civilização ocidental, como de resto também não poderia invalidar-se a especificação de capacidades proposta por alguém cuja formação cultural está ligada ao contexto da civilização oriental.

Sem embargo, o problema não parece consistir no tipo de vida boa ou se alguma visão acerca da vida boa 
é veicula por essa ou aquela proposta. A questão aparenta ficar mais bem colocada quando o seu foco passa a ser o de saber se é possível identificar interesses comuns a toda humanidade cuja proteção valha a pena defender. Ou se não.

Se se reconhece tal possibilidade, então a crítica inevitavelmente tomará a forma de um argumento autorrefutante, já que tanto a proposta ocidental como a oriental sempre cairão na factibilidade de veicular o tipo de vida boa relacionada ao contexto cultural do seu propositor. Se não se reconhece a possibilidade nem a viabilidade de identificá-los, então não será possível igualmente reconhecer, relembrando Kant (2003, p. 77), que todos os seres humanos possuem uma dignidade comum, e sim que alguns possuem uma dignidade e outros um preço conforme determinem as contingências sociais e culturais da sua comunidade.

\section{A SAÚDE SEGUNDO A ABORDAGEM ACTION-THEORETIC DE LENNART NORDENFELT}

O outro aporte teórico no qual se sustentou Venkatapuram ao propor a saúde como metacapacidade foi a abordagem da teoria da ação proposta por Lennart Nordenfelt.

Nordenfelt inicia a sua proposta de saúde observando que as pessoas somente costumam refletir acerca do significado da saúde quando ela não está presente; quando há em seu lugar, ao contrário, a dor e a inaptidão, as duas percepções humanas mais imediatas a respeito da doença (VENKATAPURAM, 2013, p. 273).

Nordenfelt rejeita a ideia de dor como conceito chave a partir do qual deve ser elaborada a definição cientificamente adequada da saúde. Isto porque nem toda a dor sentida pelos indivíduos, argumenta, provém necessariamente de uma inaptidão mais global, embora a inaptidão possa causar alguma espécie de dor ou a permanência da dor possa conduzir a um quadro de inaptidão (NORDENFELT, 2001, p. 67).

A dor de cabeça, por exemplo, representa verdadeiramente uma sensação de sofrimento e desconforto sentida pelo ser humano, mas não é correto pressupor que a sua existência atesta uma inaptidão cerebral mais ampla, embora possa indicar de forma bastante consistente a existência daquela (VENKATAPURAM, 2013, p. 273).

Para Nordenfelt, a inaptidão é o marco inicial, e ele a define como a noção negativa que pressupõe o conteúdo semântico positivo do seu oposto, a aptidão. Assim, estar saudável passa a representar a ideia de que o indivíduo possui aptidão para realizar certas coisas, e estar doente passa a denotar a ideia de que o indivíduo está inapto para realizar essas mesmas coisas (NORDENFELT, 2001, p. 67).

A partir daí, Nordenfelt passa a questionar quais atividades, e que tipo de atividades, uma pessoa saudável deve realizar (NORDENFELT, 1984, p. 18; NORDENFELT, 2000, p. 80).

$\mathrm{Na}$ busca de uma resposta para essa questão, ele concentra sua análise basicamente sobre os objetivos ou 
intenções visados pelo homem com a realização dessas atividades, o que ele chama de metas vitais. Isto é, Nordenfelt considera que a ação humana é orientada para a concretização de metas vitais, e a resposta para a pergunta acerca de quais atividades uma pessoa saudável deve estar apta a realizar tem que perpassar necessariamente pela investigação acerca do que sejam essas metas vitais (NORDENFELT, 1987, p. 53).

Em vista de proceder a essa especificação, ele afasta por um lado a ideia de que tais metas sejam a satisfação de necessidades básicas. Por outro, também rejeita que a satisfação de desejos constitua esse conteúdo importante.

Ao contrário disso tudo, ele defende a meta vital de um indivíduo como sendo um estado de coisas que é tanto um componente, como de outra forma uma necessidade para uma pessoa viver uma vida minimamente decente, incluindo evidentemente mais do que a mera sobrevivência (VENKATAPURAM, 2013, p. 273).

Recapitulando as ideias principais articuladas até aqui, é possível dizer que uma pessoa é saudável, segundo Nordenfelt, somente se ela tem a aptidão de poder realizar as metas vitais necessárias e suficientes para seu bem-estar mínimo.

De outro modo: "A é saudável se, e somente se, A tem a aptidão, dadas as circunstâncias normais, de realizar suas metas vitais, isto é, o conjunto de metas que são necessárias e conjuntamente suficientes para a sua felicidade mínima" (tradução nossa) (NORDENFELT, 1987, p. 90). Embora a saúde seja definida por Nordenfelt como a aptidão para realizar metas vitais, a não realização das referidas metas não induz um suposto estado de inaptidão, de doença. Para uma pessoa ser considerada doente, é imprescindível que ela não possua a aptidão de segunda ordem necessária para adquirir a aptidão de primeira ordem para atingir metas vitais (VENKATAPURAM, 2013, p. 273).

Esta é uma ideia complexa que se torna mais límpida por meio de exemplos. Imagine que uma determinada pessoa, por exemplo, tenha fraturado uma de suas pernas praticando futebol. Em princípio, a perna fraturada não poderá ser utilizada temporariamente para nada (inaptidão de segunda ordem) e, em razão disso, a pessoa ficará impedida de locomover-se, de praticar esportes dependentes dos membros inferiores (inaptidão de primeira ordem), dentre outras atividades (VENKATAPURAM, 2007, p. 44).

Agora suponha que se essa mesma pessoa, após realizar tratamento médico por algum tempo, recuperese da fratura e volte a utilizar a perna (aptidão de segunda ordem), voltar a caminhar (aptidão de primeira ordem) dependerá apenas da reaprendizagem de tal atividade (VENKATAPURAM, 2007, p. 44).

Em outro contexto, se eventualmente a gravidade da fratura foi de tal modo intensa que a perna dessa pessoa necessitou ser amputada (inaptidão total de segunda ordem), ela jamais poderá voltar a caminhar, pelo menos não do modo convencional, e assim será considerada uma pessoa doente, uma pessoa que não possui a aptidão de segunda ordem (possuir as duas pernas) necessária para adquirir a aptidão de primeira ordem 
(locomover-se) para concretizar suas metas vitais (VENKATAPURAM, 2007, p. 44-45).

Se, ainda diante desse mesmo contexto, essa pessoa cuja perna foi amputada reaprender a locomover-se utilizando algum instrumento de apoio, ela já não poderá mais ser considerada doente terminantemente, salvo quanto ao período em que esteve reaprendendo a caminhar.

Reconhecer a diferença entre uma inaptidão temporária e outra definitiva é fundamental para compreender-se o estado de saúde ou de doença de um indivíduo. Isso porque em um primeiro momento a pessoa é considerada inapta e temporariamente doente, mas após receber os cuidados necessários para sua recuperação, a condição de temporária inaptidão deixa de existir tornando-se factível mais uma vez a busca pela realização das metas vitais.

Já na segunda situação, a pessoa é considerada definitivamente doente porque, mesmo recebendo os cuidados necessários para a sua recuperação, perdeu de forma total a possibilidade de utilizar a perna fraturada (inaptidão de segunda ordem absoluta). Essa condição de absoluta inaptidão só deixa de existir caso reaprenda a caminhar com o auxílio de instrumentos.

Com efeito, a intenção de Nordenfelt com a proposição deste esquema é deixar claro que uma pessoa somente pode ser considerada doente quando as suas aptidões para agir são constrangidas e quando, dentro de circunstâncias normais dadas, lhe falta a aptidão para aprender a superar tal constrangimento (VENKATAPURAM, 2007, p. 44-45).

Uma pessoa encontra-se doente temporariamente quando está aprendendo a superar o constrangimento/inaptidão que lhe impede de realizar as suas metas vitais; e está definitivamente doente quando se encontra totalmente impedida de realizar suas metas vitais e impedida de aprender a superá-las.

O indivíduo que perde uma das pernas e não consegue aprender uma nova maneira de locomover-se está definitivamente doente; aquele que perde uma perna, mas reaprende a locomover-se com o auxílio de algum tipo de instrumento não pode ser considerado doente, salvo quanto ao período de reaprendizagem.

\section{A SAÚDE COMO METACAPACIDADE}

A ideia de conceber-se a saúde como uma metacapacidade surge a partir da identificação, por Venkatapuram, de três fraquezas fundamentais e carecedoras de complementação na proposta de Nordenfelt.

A primeira delas refere-se à ausência de especificação de um conjunto de metas ou objetivos vitais a serem concretizados por um indivíduo saudável. É dizer: se a saúde se define como a aptidão ou a habilidade de concretizar metas vitais, quais exatamente são as metas que um indivíduo saudável deve estar apto a realizar?

A avaliação do estado de saúde dos indivíduos depende necessariamente da especificação de um conjunto de metas vitais para as quais estejam aptos a concretizar. Isto é, só se torna possível avaliar o estado de 
saúde de um indivíduo na medida em que se avalia a sua aptidão para realizar aquele conjunto mínimo de metas vitais determinadas (VENKATAPURAM, 2013, p. 273). Este é um primeiro ponto.

A segunda questão relaciona-se com cláusula da "given standard circumstances" ("dadas as circunstâncias normais") inserida por Nordenfelt em seu conceito de saúde. Venkatapuram acusa-lhe, quanto a esse ponto, de ter advogado por uma espécie de relativismo social e cultural na sua definição de saúde.

Isso porque se a saúde representa a aptidão de um indivíduo para realizar o seu conjunto de metas vitais em dadas circunstâncias, então o nível de sua realização estará sujeito invariavelmente ao poder de influência dessas circunstâncias. Quanto mais conflitante forem as suas metas vitais com aquelas circunstâncias, menor será o seu nível de realização, e quanto mais alinhadas com aquelas circunstâncias dadas, maior será o nível de sua realização.

Mais ainda. Se as escolhas que os indivíduos fazem, dependem das opções a si disponíveis em dadas circunstâncias, então a eleição de um conjunto de metas vitais necessariamente será determinada pelo contexto cultural e pelas práticas sociais na qual estão imersos (VENKATAPURAM, 2011, p. 63).

A terceira fraqueza identificada por Venkatapuram refere-se à complicada relação entre as metas vitais e a felicidade mínima dos indivíduos. De fato, Nordenfelt afirmou que uma pessoa A somente é saudável se tem a aptidão, dadas as circunstâncias normais, de realizar suas metas vitais, de concretizar o conjunto de metas que são necessárias e conjuntamente suficientes para a sua felicidade mínima.

Ocorre que se uma pessoa tiver estabelecido para si metas vitais humanamente irrealizáveis, a não realização de tais objetivos implicará em infelicidade e, por consequência, fá-la-ia ser considerada doente quando, em verdade, é sã (VENKATAPURAM, 2013, p. de internet).

E como Venkatapuram sugere, então, que se solucionem estes três problemas fundamentais apontados no pensamento de Nordenfelt? Integrando esta teoria da saúde com a abordagem das capacidades de Amartya Sen e Martha Nussbaum.

Com efeito, o autor observa, quanto ao primeiro problema, que a lista das dez capacidades centrais de Nussbaum serve bem ao propósito da necessidade de especificação das metas vitais a serem concretizadas pelos indivíduos saudáveis. Isso porque a referida lista, argumenta, constitui verdadeiramente um conjunto de capacidades humanas básicas correspondentes às exigências mínimas da dignidade do ser humano.

Por outro lado, nota também que a adoção dessa lista de capacidades como o conjunto de metas vitais lacunoso de Nordenfelt possibilita a superação do problema do relativismo cultural presente em sua concepção de saúde. Isto é, ao elaborar uma lista contendo dez capacidades centrais das quais todos os indivíduos devem gozar de forma mínima não importa onde estejam, Nussbaum rejeita a possibilidade de que tais capacidades sejam totalmente determinadas pelas práticas e convenções culturais das diferentes sociedades, superando assim o 
equívoco de Nordenfelt.

Quanto ao último problema, Venkatapuram propõe a substituição da ideia de metas vitais pela noção de capacidades humanas centrais, isso com vista a impossibilitar que a partir dessa transformação teórica um indivíduo saudável venha a ser considerado doente simplesmente porque não logrou realizar uma meta vital humanamente irrealizável.

E assim, após completar as fraquezas e superar os problemas do pensamento de Nordenfelt, sugere que a saúde passe a ser concebida como a capacidade de uma pessoa para realizar as dez capacidades humanas centrais; como uma metacapacidade ou uma capacidade de segunda ordem necessária e indispensável para a realização das capacidades de primeira ordem (as dez capacidades humanas centrais) (VENKATAPURAM, 2013, p. de internet).

O ser humano saudável, para si, é aquele que possui a oportunidade real de poder realizar concretamente todas as dez capacidades humanas centrais; e o doente, ao contrário, é aquele que não possui nem a oportunidade real de poder realizar de modo concreto as dez capacidades humanas centrais nem a oportunidade de poder aprender a superar tal limitação em sua liberdade.

Contrariamente a Venkatapuram, entendemos haver a necessidade de restrição da lista de capacidades a serem realizadas pelos indivíduos como tradução do seu estado de saúde ou morbidez.

E isso por duas ordens de razões. Primeiro, porque a lista de Martha Nussbaum acerca das dez capacidades centrais é bastante extensa para a determinação do estado de saúde de um indivíduo, pois abrange várias condições, circunstâncias e bens que, acaso inexistentes, não farão necessariamente doente um indivíduo saudável - veja-se, por exemplo, o caso da capacidade de participação nas escolhas políticas que efetivamente governam a própria vida.

Depois, adotar-se tal perspectiva implicaria na exata reprodução da falha apontada no conceito de saúde da OMS e que tem a ver com a transformação de variadas questões econômicas, políticas e sociais em condições mórbidas - veja-se, a este título, a capacidade de estar seguro de assaltos violentos, incluindo agressão sexual.

Ora, é preciso ter em conta que a falta de participação política ou a ausência de segurança necessária à manutenção da integridade corporal, embora possam influir de maneira decisiva no estado de saúde de um indivíduo, não constituem uma capacidade que, acaso inexistente, venha a anotar a condição de morbidez de um indivíduo. E a razão é simples: porque diretamente não têm nada a ver com saúde e doença, e sim com política e direito.

Não se pode dizer que um indivíduo desabrigado se encontra necessariamente doente em razão de não possuir uma moradia digna; é possível dizer, sim, que as chances de vir a desenvolver uma condição morbígena são maiores devido a sua situação de maior risco social. 
Em resumo, é fundamental distinguir o que são questões de saúde e o que são questões políticas, econômicas, jurídicas e sociais influentes sobre o estado de saúde.

Dentro do conjunto das dez capacidades básicas de Martha Nussbaum, é possível identificar as capacidades (oportunidades reais) das quais a pessoa saudável pode se valer para consecução do seu plano de vida e que, inexistindo, denotam o estado de morbidez.

Por razões metodológicas, sumariaramos estas capacidades da seguinte forma:

1. Nutrição: ser capaz de estar bem nutrido, e ter a oportunidade em sentido biológico de poder superar um eventual estado de desnutrição passageira;

2. Locomoção: ser capaz de se mover livremente de um lugar para outro, e ter a oportunidade de poder reaprender a mover-se de modo independente, com ou sem ajuda de equipamentos;

3. Reprodução: ser capaz de se poder reproduzir, e ter a oportunidade de poder reaprender uma nova maneira de se reproduzir em caso de infertilidade temporária;

4. Comunicação: ser capaz de comunicação, e ter a oportunidade de poder reaprender a se comunicar com outros indivíduos, usando ou não todos os sentidos;

5. Raciocínio: ser capaz de pensar e raciocinar, e ter a oportunidade de poder reaprender a utilizar de modo pleno as faculdades mentais necessárias à construção de sentido mental;

6. Emoções: ser capaz de possuir um emocional livre em sentido psiquiátrico, e ter a oportunidade de poder se libertar de traumas e experiências negativas obstaculizantes da saúde psicológica.

Este é o conjunto elementar de capacidades que remanesce decisivo para a determinação do estado de saúde ou morbidez de uma pessoa. Sobre ele, no entanto, três breves registros.

Primeiramente, é preciso ter em conta que a lista de capacidades apresentadas está relacionada a funções que devem ser desempenhadas pelos indivíduos como necessárias a sua manutenção vital em um mundo de partilha e convivência obrigatória, e não a órgãos e estruturas orgânicas.

A ausência de apenas uma das capacidades listadas já é suficiente para denotar o estado de morbidez, a ser temporário conforme consista na impossibilidade de uso imediato de uma capacidade determinada, ou absoluto conforme se anulem as possibilidades de se poder reaprender a utilizar a capacidade em questão.

Depois, é imperioso notar que por estarem relacionadas a funções, as capacidades listadas acabam por levar em conta os múltiplos e diversificados fatores que conduzem tanto a uma impossibilidade imediata e temporária de sua realização (doença temporária), como a impossibilidade de se poder reaprender uma nova maneira de utilizá-las (doença absoluta).

Isto é, a perda da capacidade de estar bem nutrido, assim como a perda da oportunidade de se poder reaprender uma nova maneira de nutrir-se adequadamente tanto podem ser causadas por uma rejeição natural e 
genética do organismo a determinados tipos de alimentos, quanto pela degradação total do sistema digestivo provocada por uma bactéria encontrada em água não tratada e inadvertidamente consumida.

A perda da capacidade de raciocínio e a perda da oportunidade de se poder reaprender a utilizar de modo pleno a potencialidade cerebral tanto podem ser oriundas de uma doença mental adquirida no decurso do tempo, tal como o mal de Alzheimer, como podem originar-se de um acidente de trânsito provocado por um condutor agressivo.

Em síntese, a perda de uma função, não em sentido biológico estrito, mas em um sentido biossocial como se intencionou, pode ocorrer por milhares de motivos, e a listagem das capacidades do modo como configurada procurou atender a esse reclamo que, decerto, já vem sendo pugnado há algum tempo - considerar as questões políticas, sociais, econômicas, culturais e mesmo jurídicas incidentes sobre a qualidade da saúde.

Por fim, é necessário verificar que o conceito de capacidade conjugado com a abordagem de saúde proposta por Nordenfelt tem vindo a significar durante toda esta construção, basicamente, poder realizar-se algumas coisas e ter a 'oportunidade de poder aprender...' uma maneira de realizá-las novamente. Ou seja, liberdade.

No caso das capacidades centrais de saúde, como agora passar-se-á a designar aquele conjunto, o não exercício de uma capacidade não representa nem de modo indiciário um suposto estado de doença de um indivíduo. A bem da verdade, o seu exercício nem sequer é considerado para este efeito, por isso mesmo toda capacidade subsiste como oportunidade.

O que importa para efeitos de determinação do estado de um indivíduo é verificar se lhe falta uma capacidade de saúde, isto é, se tanto não pode executar de modo imediato e temporário algumas das atividades listadas acima como, em caso positivo, se the restam anuladas as oportunidades de aprender uma nova maneira de executá-las.

Veja-se a capacidade de comunicação, por exemplo. Não querer-se comunicar com os demais é bastante diferente de 'não se poder comunicar com os demais' (doença temporária) e de 'não se ter a oportunidade de poder reaprender' (doença absoluta) a comunicar-se novamente com os outros. A doença não está no 'não querer', e, sim, no 'não poder' e no 'não se ter oportunidade de poder reaprender', caracterizados, o primeiro, na impossibilidade imediata de comunicação e, o segundo, no esgotamento absoluto de qualquer nova possibilidade de comunicação.

E isto vale para todas as capacidades, incluindo a própria reprodução e a sua suposta peculiaridade de permitir que os indivíduos anulem completamente a possibilidade de poderem reaprender uma maneira nova de se reproduzir - basta se considerar, a este título, a reversibilidade da vasectomia, o procedimento da fertilização in vitro para mulheres já esterilizadas, ou mesmo outros procedimentos alternativos de reprodução exógena como 
"barriga de aluguel", etc.

A única circunstância que se deve levar em conta na capacidade de reprodução é que o 'não poder reproduzir-se' pode ser ocasionado voluntariamente, o que não pode ser interpretado como sinal de uma condição mórbida.

\section{IMPLICAÇÕES}

Partindo-se da concepção de saúde como metacapacidade, é possível extrairmos três implicações fundamentais: um novo olhar para o significado real do conceito de privação de saúde; uma distinção epistemológica entre os conceitos de doença e enfermidade; e as consequências disto para o Direito.

\section{Saúde e Desenvolvimento: Um novo olhar sobre a privação}

A garantia de acesso a bens ou recursos, independentemente do conteúdo ou forma assumidos, de modo algum representa incremento imediato na vida que as pessoas levam, e essa é uma preocupação muito mais ampla de Sen envolvendo a problemática assimilação da ideia de desenvolvimento com crescimento ou econômico (SEN, 2000, p. 21).

Se a riqueza deve ser tomada como um item de importância intrínseca na vida das pessoas, como explicar que indivíduos notoriamente mais ricos não possam desfrutar de uma vida mais longa e melhor? Essa é uma questão capital no pensamento de Amartya Sen e que de fato parece romper com um paradigma equivocado a respeito da noção de desenvolvimento e da noção de pobreza.

Ora, se a vida das pessoas constitui uma combinação de vários 'seres' e 'fazeres' (funcionamentos), e se os seus desejos e vontades desempenham papel fundamental na determinação de quais funcionamentos lhes são relevantes, então a tarefa do desenvolvimento consiste - reconhecerá Sen - em expandir a liberdade (oportunidade) real de concretização do estilo de vida que lhes pareçam mais valiosos (SEN, 2000, p. 19-21).

Isto é, a tarefa do desenvolvimento é propiciar uma expansão do conjunto de vetores de funcionamentos (conjunto capacitório) que uma pessoa tem a seu dispor para escolher conforme o seu projeto de vida, independentemente de ter escolhido um e rejeitado os demais.

Ora, estando bem definido que a tarefa do desenvolvimento é conceder mais liberdade aos indivíduos, então também parece ser adequado e igualmente necessário considerar que o indispensável processo de tomada de decisão deva ser justo, equitativo e sem interferências externas (SEN, 2000, p. 19).

É dizer, a liberdade precisa ser satisfeita não só quanto à oportunização da possibilidade de escolha e realização de um estilo de vida especialmente valioso; é imprescindível que a tomada de decisão acerca do melhor caminho a ser seguido também seja livre de interferências externas, e esse é um aspecto tão importante quanto o 
outro (SEN, 2000, p. 19).

Não adianta aumentar a possibilidade que um indivíduo tem de poder concretizar o seu desejo de ser médico ou advogado, por exemplo, se os seus genitores lhe obrigam invariavelmente a seguir a carreira militar, como também não adianta lhe possibilitar ser um oficial militar, caso queira, se não possui o serviço básico estatal para ingressar na carreira.

Sem embargo, essa é uma ideia que revela a percepção de Sen segundo a qual a liberdade desfrutada pelas pessoas na sociedade é dependente e condicionada às influências das disposições sociais, econômicas e culturais, e, portanto, promover o desenvolvimento representa corrigir ou aperfeiçoar os processos e oportunidades da liberdade em todos esses segmentos importantes da vida humana.

Bem, se desenvolvimento significa a expansão da liberdade (tanto na sua função constitutiva como, e principalmente, na sua função instrumental), então o que significa a pobreza ou privação (SEN, 2000, p. 55-56)?

Ora, assim como restou claro que a ideia de desenvolvimento não pode estar associada à de crescimento econômico, a ideia de pobreza ou privação social também não pode estar relacionada com a ideia de falta de recursos econômicos. A razão é intuitiva: o incremento da riqueza das pessoas não é independente do seu preparo para convertê-la em boa vida, e, se assim o é, parece então mais adequado compreender a pobreza não antes como falta de recurso, mas, verdadeiramente, como uma privação de capacidades (ou privação de oportunidades para escolher e poder mudar concretamente de vida) (SEN, 2000, p. 114-119).

Esta é uma mudança de pensamento que tem impacto profundo sobre a ideia de saúde e privação em saúde que pretendemos defender. Isto porque, se a saúde deve ser assimilada como uma espécie de metacapacidade, e a doença deve significar um obstáculo tanto à oportunidade de poder concretizar as capacidades centrais de saúde como à oportunidade de poder aprender um modo de superar esse limite imposto, a privação de saúde somente existirá quando o motivo fundamental de não superação da limitação for de ordem necessariamente extraorgânica.

O indíviduo que deixa de possuir a oportunidade real (metacapacidade) de poder concretizar as demais capacidades centrais de saúde encontra-se temporariamente doente. $\mathrm{O}$ indivíduo que deixa de possuir a oportunidade de poder aprender uma maneira de superar tal limitação encontra-se absolutamente doente.

A doença somente se torna um problema social quando restam completamente anuladas, por motivos extraorgânicos, as oportunidades que um indivíduo possui de poder aprender uma maneira de superar a metaincapacidade que lhe impede de concretizar as suas capacidades centrais de saúde.

Sistematizando-se as ideias, poder-se-ia dizer que a privação de saúde consiste, portanto, em uma ausência de oportunidade de poder se prevenir de doenças e enfermidades e manter o bom funcionamento das capacidades centrais de saúde, quanto uma ausência de oportunidade de se poder aprender a superar uma 
determinada limitação fisiológica, isto tudo por motivos não relacionados ao organismo ou à vontade individual.

\section{Doença Versus Enfermidade}

A doença e a enfermidade, pelo menos na perspectiva defendida neste estudo, são conceitos distintos, embora intimamente relacionados e vinculados. No que concerne à doença, o conceito deixou claro tratar-se de um obstáculo à oportunidade de poder concretizar capacidades centrais de saúde e, simultaneamente, à oportunidade de poder-se aprender uma maneira de superar este limite. A enfermidade, ao contrário, identifica-se com uma ideia mais restrita de patologia ou disfunção biológica como é costumeiramente utilizada na prática médica.

Em verdade, essa é uma distinção que deve ser necessariamente percebida pelo agente público, seja por ocasião do desenho das políticas sociais de saúde, seja por ocasião da delimitação legislativa dos serviços públicos a que deve o Estado se obrigar no campo da saúde.

Isto porque o indivíduo portador de uma enfermidade que possui a oportunidade de poder aprender, caso queira, uma maneira de superar os efeitos deletérios e impedientes ocasionados por uma patologia não se encontra, rigorosamente falando, doente.

Vejamos o seguinte exemplo.

Imagine-se que determinado indivíduo, professor universitário renomado, seja portador de uma grave enfermidade rara que afeta o funcionamento dos seus rins de modo a impedir-lhes de filtrar adequadamente as impurezas do seu sangue. Imagine, também, que esse mesmo indivíduo possui renda suficiente para custear os medicamentos necessários dos quais precisa e o Estado do qual é nacional também fornece tratamento gratuito de hemodiálise para os portadores de doença hepática, fatores que lhe permitem ter a oportunidade de poder concretizar, caso queira, as demais capacidades básicas apontadas por Nussbaum como necessárias para levar-se uma vida razoavelmente adequada.

Suponha, no entanto, que um tratamento bastante dispendioso destinado à cura total dessa enfermidade passe a ser oferecido no mercado, e que esse indivíduo não tenha condições de custeá-lo e nem o Estado do qual é nacional preveja a sua inclusão nos protocolos clínicos da rede de saúde pública.

Em uma situação como esta, a atuação do Estado deve estar voltada para a eliminação e erradicação da enfermidade no organismo do indivíduo, ou deve estar restrita à garantia e disponibilização dos cuidados de saúde suficientes a que se possa aprender uma maneira de superar a limitação fisiológica imposta pela enfermidade? Este é um questionamento interessante que, ao cabo, merece uma resposta negativa.

Isto porque se a atuação política do Estado no planejamento das ações sanitárias estiver voltada para a eliminação e erradicação da enfermidade no organismo de um indivíduo, então os serviços públicos e as 
obrigações assumidas no campo das prestações deverão ser tanto mais abrangentes quanto mais necessário se fizer para remoção dessa enfermidade; perspectiva potencialmente perigosa para a manutenção financeira dos demais serviços sociais.

E aí, seguindo-se essa perspectiva, no caso do exemplo retratado, o Estado tanto deverá custear a cura da enfermidade hepática sofrida pelo indivíduo quanto deverá providenciar a sua posterior inclusão nos protocolos de tratamento da rede de saúde pública, hipótese também válida para o caso dos portadores de HIV.

Tendo-se claro, no entanto, que a doença é quem deve constituir o marco de referência desta atuação muito embora não faça parte do núcleo do direito, como já veremos -, então os serviços públicos oferecidos passam a encontrar limites nas exigências de sustentabilidade fiscal e equilíbrio orçamental.

Veja-se que eleger a doença como referencial não implica considerar o Estado também obrigado a erradicá-la nos casos em que se tornou absoluta; implica somente que deva dispensar os recursos necessários a aliviar, ou mesmo, se possível neutralizar a debilidade intrínseca percebida pelo indivíduo nesta condição.

Em um contexto como este do exemplo, a oferta de serviços de hemodiálise e de cuidados médicos mais amplos já se torna suficiente para garantir que o individuo enfermo tenha a oportunidade real de poder aprender uma maneira de superar as limitações impostas pelo mau funcionamento dos seus rins.

Não significa isto, entretanto, os cuidados de saúde devam ser restringidos somente aos indivíduos que se encontram doentes com necessária exclusão dos que se encontram enfermos - se assim fosse, as ações de prevenção de saúde cujo alvo são mesmo os indivíduos saudáveis restariam inevitavelmente injustificadas.

Em verdade, perceber a diferença conceitual e substancial entre a doença e a enfermidade encontra fundamento na necessidade de recuperar-se a noção elementar de que ao Estado não é dado, por notória impossibilidade fática, garantir a própria saúde, no que vai descambar essencialmente se tiver suas ações voltadas para a erradicação da enfermidade no organismo dos indivíduos.

\section{Significados e Consequências para o Direito}

Entender a saúde como uma metacapacidade significa compreendê-la mais do que a mera ausência de doença, significa assumi-la, essencialmente, como uma aptidão para realizar certas coisas, uma habilidade para realizar certas funções de caráter biossocial necessárias à liberdade dos indivíduos.

Uma capacidade central de saúde é funcional em sentido biossocial porque dependente de um determinado funcionamento do organismo que somente se projeta e adquire sentido em um mundo de partilha e convivência necessária - basta se pensar na falta de sentido biossocial da comunicação, da emoção ou da reprodução para um indivíduo isolado.

Nestes termos, proteger a saúde passa a significar, segundo esta perspectiva, uma proteção jurídica em 
sentido amplo às funções (capacidades) biossociais da nutrição, locomoção, reprodução, comunicação, raciocínio e emoções; funções que são dependentes de certo funcionamento do organismo, mas que se projetam e só adquirem sentido porque essenciais à concretização de planos de vida em um mundo de partilha e convivência humana obrigatória.

Quer dizer, a proteção jurídica destas funções, destas capacidades de saúde, isto por meio de subdireitos de defesa, de proteção e de promoção, representa uma concessão extraorgânica indispensável dos meios necessários a que os indivíduos possam manter seu organismo minimamente apto para a consecução de projetos de vida.

Isto significa, portanto, que o conteúdo do direito se esgota quando estas funções encontram-se protegidas, nem mais, nem menos. É dizer, o conteúdo do direito, esquadrinhado em subdireitos de proteção, defesa e promoção, realiza-se quando o Estado logra garantir os meios indispensáveis à guarita destas funções biossociais.

Ora, esta é uma mudança que produz consequências. Desde logo porque, primeiramente, significa a retirada da ideia de doença e de enfermidade do núcleo do direito, isto é, a doença ou a enfermidade deixam de ter significação jurídica, deixam de fazer parte integrante do núcleo fundamental do direito.

Para a saúde como metacapacidade, o direito à proteção da saúde não se satisfaz com a total proteção do organismo contra a ocorrência de doenças ou enfermidades; o conteúdo se realiza quando o Estado disponibiliza os meios indispensáveis a que o indivíduo aprenda a superar uma determinada limitação fisiológica incidente sobre uma das suas capacidades centrais de saúde (doença temporária), ou a que consiga aliviar os efeitos deletérios de uma doença absoluta.

Sem embargo, retirar o conceito de doença e de enfermidade do conteúdo do direito à proteção da saúde significa eliminar qualquer possibilidade de se exigir do Estado uma total e absoluta proteção contra a morbidez e, ao final, contra a própria morte; seu dever fundamental exaure-se quando dispõe aos indivíduos as condições necessárias para que tenham condições de reaprender a utilizar suas capacidades centrais de saúde em caso de doença temporária, ou, ainda, que tenham condições de amenizar as dificuldades em caso de doença absoluta.

Por outro lado, considerar o conceito de doença uma referência para a elaboração das políticas de saúde não implica em incluí-lo no núcleo do direito. Em verdade, denota tão somente uma própria exigência da essência deste direito, que passa a considerar a doença não mais como condição humana a ser evitada através da juridicidade, mas como condição balizadora da ação política oriunda da própria juridicidade.

Em outros termos: se o núcleo do direito exige um determinado comportamento estatal; se este comportamento realiza-se quando disponibilizados os meios indispensáveis à proteção das capacidades centrais 
de saúde; e se esta proteção perfaz-se no plano prático na figura de políticas sociais e de subdireitos, tem-se então que a ação política do Estado deve limitar-se à disposição pública dos meios necessários à garantia da prevenção, manutenção e recuperação das capacidades centrais de saúde dos indivíduos, ou, em uma trágica hipótese, da suavização dos efeitos negativos de uma doença absoluta.

Ideia que irá repercutir profundamente sobre a noção de privação de saúde.

Ora, se a noção de privação de saúde exprime a ideia de uma ausência de oportunidade de poder-se prevenir e manter o bom funcionamento das capacidades centrais de saúde, quanto de poder-se aprender a superar uma determinada limitação fisiológica ou de suavizar os efeitos de uma doença absoluta, isto por motivos não relacionados ao organismo ou à vontade individual, tem-se então que garantidos os meios indispensáveis à guarita destas funções biossociais por força do compromisso constitucional não há que se falar em privação.

Isto é, se o Estado simplesmente realiza o conteúdo do direito à proteção da saúde nos termos que aqui têm sido colocados, consequentemente também terá solucionado o problema da privação.

Mais uma vez é importante recordar que ao Estado não é dado garantir a própria saúde ou uma proteção absoluta contra a ocorrência de doenças ou enfermidades; sua tarefa como entidade política limita-se tão somente à garantia pública de meios de proteção, significando isto que dele não se poderá exigir, pelo menos judicialmente, além do que este conteúdo nuclear comporta.

Em suma, assumir o direito à proteção da saúde como um direito à proteção jurídica ampla das capacidades centrais da nutrição, locomoção, reprodução, comunicação, raciocínio e emoçôes significa expressar a garantia importante, porém limitada, da intervenção do Estado nestas relevantes questões de vida e morte.

\section{CONSIDERAÇÕES FINAIS}

Em 1963, Stephen Hawking, àquela altura apenas um doutorando em física teórica e cosmologia, fora diagnosticado portador da gravíssima esclerose lateral amiotrófica, enfermidade que segundo os médicos responsáveis the concederia somente mais dois anos de vida. Ocorre, entretanto, que contrariando todas as expectativas, Hawking doutorou-se em 1966 com uma tese que revolucionou a agenda de pesquisa da sua área e que o projetou como um dos maiores e mais notáveis cientistas já produzidos pela humanidade.

O exemplo de Hawking é interessante não só porque demonstra as potencialidades e virtudes ainda desconhecidas da mente humana, mas, sobretudo, porque nos obriga a repensar fundamentalmente o processo saúde-doença e os significados da saúde, da doença, e dos seus limites.

Com efeito, encontra-se verdadeiramente doente o indivíduo que, a despeito das malformações congênitas do seu organismo ou das consequências negativas de uma enfermidade agressiva, aprendeu uma nova maneira de desempenhar as funções necessárias a sua manutenção vital em um mundo de partilha e convivência 
obrigatória? Esta é uma pergunta fundamental.

De maneira geral, a análise deste e de outros casos semelhantes nos tenta a considerar que um indivíduo, cujo organismo não funciona de acordo com o esperado para o ser humano ou cujo mal-estar é evidente em virtude de uma enfermidade - encontra-se indiscutivelmente doente, e o exemplo de Hawking é importante porque nos convida a refletir sobre o que releva decisivo para a determinação dos estados de saúde e de doença.

Com efeito, a saúde subsiste uma condição desejável porque nos permite ter a oportunidade de realizar algumas atividades essenciais que um mundo de partilha e convivência obrigatórias impõe. Ora, não significa isto que o bom funcionamento do organismo ou o bem-estar individual sejam irrelevantes. Não. Significa somente que não são determinantes para a identificação da condição de saúde ou de doença, e tão somente isto.

Preocupa-nos saber que um determinado indivíduo não consegue se comunicar em razão das sequelas negativas provocadas por uma enfermidade grave da qual está acometido. Preocupa-nos mais ainda e por óbvias razões humanitárias saber que esta impossibilidade possivelmente vai fazer-se acompanhar de um evidente e justificado estado de mal estar. Entretanto, nossa preocupação maior consiste mesmo em saber que este determinado indivíduo não consegue se comunicar em um mundo de partilha e convivência obrigatória onde a capacidade de comunicação é essencial para o seu desenvolvimento.

E esta nos parece ser a vantagem principal do conceito de saúde como metacapacidade: consegue, observando as exigências epistemológicas antes reconhecidas, transformar a nossa percepção acerca do processo saúde-doença.

\section{HEALTH AS META-CAPABILTY: REDEFINING THE LEGAL ASSET}

\section{Abstract}

The article aims, on one hand, redefine the legal asset 'health' from the proposal of Venkatapuram and, on the other, discuss some of its implications. To do so, we review the theoretical bases used by Venkatapuram (Amartya Sen and Nussbaum theory of capabilities, and the Nordenfelt holistic health concept), propose some adjustments to the concept, and finally we analyze their main normative implications. It is used primarily the method of literature review.

Keywords: Capabilities Theory. Holistic Concept of Health. Health as a Meta-capability. Social Rights.

\section{REFERÊNCIAS BIBLIOGRÁFICAS}

CLARK, David A. The capability approuch: its development, critiques and recent advances. Global Poverty Research Group. Working Paper 32 (GPRG-WPS-032), 2006. Disponível em: 
<http://www.gprg.org/pubs/workingpapers/default.htm>. Acesso em: 10.04.2014.

NORDENFELT, Lennart; LINDAHL, Börje Ingemar Bertil. Health, disease, and causal explanations in medicine. Dordrecht: D. Reidel, 1984.

On the nature of health. An action-theoretic approach. Dordrecht: Springer Science, 1987.

2000.

Action, ability and health. Essays in the Philosophy of Action and Welfare. Dordrecht: Springer Science,

Health, science, and ordinary language. Amsterdam: Rodopi, 2001.

NUSSBAUM, Martha Craven; SEN, Amartya Kumar (orgs.). The quality of life. Oxford: Clarendon Press, 1993.

NUSSBAUM, Martha Craven. Capabilities as fundamental entitlements: Sen and social choice. Feminist economics, vol. 9, issue 2-3, 2003.

Creating capabilities. The human development approach. Cambridge: The Belknap Press of Havard University Press, 2011.

OLIVEIRA, Fabio Alves Gomes; GOMES, Jacqueline de Souza. "Ética e direitos humanos: um enfoque a partir da teoria das capacitações". Diversitates, Rio de Janeiro, vol. 5, n. 1, pp. 70-91, 2013. Disponível em: $<$ http://diversitatesjournal.wordpress.com/vol-05-n-01>. Acesso em: 01.02.2014.

REICHER, Stella Camlot. Capacidades e direitos humanos: uma análise conceitual sob a ótica de Martha Nussbaum. Dissertação (Mestrado em Direito) - Faculdade de Direito, Universidade de São Paulo, São Paulo, 2009.

SEN, Amartya Kumar. Equality of what? In: MACMURRIN, Sterling Moss (org.). The Tanner lectures on human value, vol. I. Salt Lake City: University of Utah Press, 1980.

Inequality reexamined. Oxford: Clarendon Press, 1992.

"O desenvolvimento como expansão de capacidades". Lua Nova, São Paulo, n. 28-29, 1993. Disponível em: <http://www.scielo.br/scielo.php?pid=S0102-64451993000100016\&script=sci_arttext>. Acesso em: 02.01.2014.

Desarollo y libertad. Trad. Esther Rabasco e Luis Toharia. Barcelona: Editorial Planeta, 2000.

Capability and well-being. In: HAUSMAN, Daniel M. (org.). The philosophy of economics. An anthology. Third ed. New York: Cambridge University Press, 2007. Disponível em: <http:/ / digamo.free.fr/hausman8.pdf\#page=276>. Acesso em: 03.03.2014.

A ideia de justiça. Trad. Denise Bootmann e Ricardo Doninelli Mendes. São Paulo: Companhia das Letras, 2011.

VENKATAPURAM, Sridhar. Health and justice: the capability to be healthy. Tese (Doutorado em Filosofia) King's College, University of Cambridge, Cambridge, 2007.

Health justice. Cambridge: Polity Press, 2011.

Health, vital goals, and central human capabilities. Bioethics, vol. 27, n. 5, pp. 271-279, 2013. Disponível em: <www.ncbi.nlm.nih.gov/pmc/articles/PMC3709132/\#fn9>. Acesso em: 03.03.2014.

Trabalho enviado em 07 de março de 2016.

Aceito em 25 de agosto de 2016. 